\title{
REASONS FOR FAILURES IN INSPECTION REPORTS FOR RESIDENTIAL BUILDS
}

\author{
JOHN TAGIILIMA $^{1}$ and FUNMILAYO EBUN ROTIMI ${ }^{2}$ \\ ${ }^{I}$ Central Building Control, Auckland Council, Auckland, New Zealand \\ ${ }^{2}$ Built Environment Engineering, School of Future Environment, Auckland University of \\ Technology, Auckland, New Zealand
}

\begin{abstract}
The construction of multi dwellings is currently a focus of the New Zealand government to address housing shortages. The intention is to build en masse whilst also keeping the buildings affordable. Affordability is not expected to compromise on quality and performance of new builds. New Zealand has a strict regime for building compliance, which helps to maintain standard of building performance. However, despite this, some buildings fail inspection during construction. There is limited understanding on the reasons for such failures. Therefore, this paper aims to provide a clear and concise understanding of why and how residential building inspections fail. The study investigates the reasons behind failed inspections by analyzing 146,000 inspection reports. The report used for the study cover January 2013 till June 2016. The data set was obtained from a major urban council in New Zealand. The results identified two key reasons for failed inspections. One is technical in nature and the other administrative, which both Council and builders must work collaboratively to achieve common compliance objectives. The study provides the construction industry with important insights into the reasons for failure of building inspections to serve as a preventative approach to non-achievement of expected residential building qualities.
\end{abstract}

Keywords: Building control, Causes, Construction, Defects, Failed.

\section{INTRODUCTION}

New Zealanders have come a long way with respect to the design and construction of residential buildings. Not so long ago, a typical New Zealand home consisted of a two or three-bedroom villa, uninsulated, with untreated timber studs and walls, standing alone on about a $700-1000 \mathrm{~m}^{2}$ section. Fast forward to the present, these buildings have either been demolished, renovated, extended, altered, or moved to make way for newly designed, warmer, and more fit for purpose buildings (Tagiilima 2016). Residential building construction works continue to increase as the population of the major cities in New Zealand grows. Residential consents have risen by approximately $14 \%$ from the previous year. Every newly designed residential building is consented, and its construction is closely monitored by Building Control Authorities (BCAs). Construction has to conform with the New Zealand Building Code otherwise, they are failed by BCAs. Failed building inspections are directly linked to extended project duration, wasted resources, and an increase in house prices (Lundkvist et al. 2014). The current study aims to provide a clear and concise understanding of why and how some residential building inspections fail. It then provides some suggestions and solutions on how failed inspections may be minimized to ensure residential buildings are safe and habitable. 


\section{LITERATURE REVIEW}

Much of international research focuses on capturing the magnitude and types of common defects at post-occupancy of residential buildings (Chong and Low 2005, Abdul-Rahman et al. 2014, Forcada et al. 2014, Carretero-Ayuso et al. 2017, Jonsson and Gunnelin 2019). Within the context of residential building construction in New Zealand, studies on post-occupancy defects were conducted by Page (2011, 2015), Rotimi (2013) and Wardle and Duncan (2017). Page (2015) reported that an average of 2.2 compliance defects are present per house with some houses recording four or more compliance defects after the issuance of Code Compliance Certificates. Despite these extensive researches, few dependable sources have established the causes of failed building inspection, particularly during the construction stage. One of the earliest works on analyzing building compliance reports in New Zealand was investigated 157 failed inspections over 48 building consents covering West and Central Auckland and showed that during the three years prior to the study, the average total building inspection failure rate was $23 \%$ and an average of 30\% in 2015. The inspection failure rate peaked in August 2015 at $35 \%$. Undertaking a wider coverage area and period, Tagiilima and Rotimi (2018) examined 146,000 inspection records extracted from Auckland Council records at different stages of residential building inspection. Tagiilima and Rotimi (2018) found about 19\% of failed inspections between 2013 and 2016. Furthermore, four significant stages of failed inspections were captured by the study investigation to include: final building inspection stage, Pre-line build, Framing and Foundation inspection stages in that order (Tagiilima and Rotimi 2018). The current study follows up on that study.

\section{RESEARCH METHOD}

This study is based on residential building inspection records from two regional areas within the Auckland Council, New Zealand (Auckland central and Papakura). The data covered January 2013 to June 2016 period, during which about 146,000 residential building inspections were conducted. The data obtained comprised of fields such as consent number, date and type of inspection undertaken, the result of the inspection, complexities of the build, and the comments from the inspector on the inspection outcome (passed or failed). The residential buildings were ranked based on a competency systems framework as R1, R2, and R3. Complexities and grouping of residential buildings in New Zealand is based on a national competency system's framework, starting with the legislative requirements through to the tools of assessment (Tagiilima and Rotimi 2018). For the purposes of this study, data from the two regional areas are combined and largely involved descriptive statistics. The data was analyzed to determine the reasons for the failure of building inspections.

\section{DATA ANALYSIS AND RESULT DISCUSSION}

As earlier mentioned, the current study follows on from Tagiilima and Rotimi (2018), where the objective was to identify common failings in inspections during the construction of residential buildings in New Zealand. In that study, the top four most commonly failed inspection stages were identified as Residential Final, Pre-line building, Framing and Foundation Inspection. The aim of the present study is to identify potential reasons for inspection failures during these four inspection stages. Data for this study was manipulated to categorize the record of failed inspections at each identified stage with respect to the type of residential projects R1, R2, and R3. The resultant pivot table is presented as Table 1 to 4 and discussed under the following subheadings corresponding to the four topmost stages at which inspections fail (Tagiilima and Rotimi 2018). 
Table 1. Common reasons for failed Residential Final Inspections.

\begin{tabular}{lccccc}
\hline Residential Final reasons for failure & R1 & R2 & R3 & Total & Total \% \\
\hline Firewalls & 1 & 0 & 0 & 1 & 0 \\
Cowls to vent & 2 & 0 & 0 & 2 & 0 \\
Laundry/seal/penetration & 2 & 1 & 3 & 6 & 1 \\
Mechanical extraction and vents & 1 & 5 & 1 & 7 & 2 \\
Restrictors to windows & 2 & 4 & 2 & 8 & 2 \\
Kitchen/hop/finishing. & 0 & 7 & 4 & 11 & 3 \\
Subfloor/braces/deck & 8 & 3 & 2 & 13 & 3 \\
Downpipes/Fixings/Spreaders & 3 & 7 & 4 & 14 & 3 \\
Hot Water Cylinder/Tundish/Straps etc & 5 & 7 & 6 & 18 & 4 \\
Vacuum Breaker & 8 & 4 & 7 & 19 & 5 \\
Landscape/footbath/cesspits/storm water & 2 & 12 & 5 & 19 & 5 \\
Bathroom non-return valves & 9 & 10 & 3 & 22 & 5 \\
Site Not Ready & 12 & 5 & 5 & 22 & 5 \\
Gully and ORG- height and haunching & 8 & 9 & 6 & 23 & 6 \\
Bathroom Seals and penetrations & 8 & 14 & 10 & 32 & 8 \\
Handrails/Barriers/ Stairs & 7 & 18 & 10 & 35 & 9 \\
Smoke Alarms & 14 & 15 & 10 & 39 & 10 \\
Paperwork Outstanding/ Minor Variations & 15 & 23 & 19 & 57 & 14 \\
Cladding Painted/penetrations/flashings/exterior & 17 & 26 & 19 & 62 & 15 \\
Grand Total & 124 & 170 & 116 & 410 & 100 \\
\hline
\end{tabular}

\section{1 “Residential Final” Inspection Stage}

'Residential final' data collection began by filtering all failed final inspection for the period of the study. Table 1 presents the data collected from each sample group: R1, R2, and R3. From the table, it can be observed that 124, 170, and 116 samples were taken from R1, R2, and R3 building complexities, respectively. Thus, a total of 410 failed Residential Final inspections were recorded with a total of 17 reasons identified for those failed inspections. A residential final inspection is the last inspection before the issuance of CCC. This is when final finishing touches are made to the building that includes areas where safety from falling is addressed. The top four most common reasons for failing at the residential final inspection stage were recorded. These include cladding issues such as cladding not painted with penetrations in the exterior and cladding not sealed as in pipes junctions. This occurs $15 \%$ of the time. In addition, flashings to the exterior meter boxes and extractor fans are often not properly weatherproofed. Secondly, $14 \%$ of all final inspection failed due to outstanding paperwork, which was a policy introduced around April 2014. Thirdly, $10 \%$ of the failed final inspection was due to smoke alarms not installed or installed in the wrong position. Finally, the fourth most common reason for failed final inspection was handrails and barriers that were not installed or do not meet the minimum requirement of the building code.

\section{2 "Pre-line" Inspection Stage}

Pre-line inspections follow cavity wrap and cladding inspections. It is important that the buildings are weathertight, and all joinery and exterior flashings have been installed properly. At this stage, the roof cladding and all roof junctions should have been weatherproofed and installed as per the manufacturer's specifications. At this stage of construction, windows and doors are to be pressure sealed and expanding foam applied after the pef rod in window and door openings. Also, inspectors will check that all insulations are in place and that the correct value and type of insulation is installed. In most cases, plumbing is part of the pre-line inspection. Pre-line Inspection is the second most failed inspection, according to Tagiilima and Rotimi (2018). There 
were 15 reasons behind failed inspections, most commonly due to outstanding paperwork (16\% of the time). Secondly, $12 \%$ of the time, pre-line inspections are failed due to high moisture in timber framing. Thirdly, failed pre-line inspections were due to the site not ready for inspection. This commonly happens when the inspector arrives and the building has not been weatherproofed. The fourth most common reason was brace systems being compromised due to activities by plumbers and electricians. For a brace system to comply with regulations, it must have a continuous top and bottom plate as well as side studs. Often, electrical and plumbing installation can penetrate these brace walls to the point where braces can no longer achieve their required bracing units and strength.

Table 2. Common reasons for Failed Preline inspections.

\begin{tabular}{lccccc}
\hline Preline Building reasons for failure & R1 & R2 & R3 & Total & Total \% \\
\hline Gully Traps & 1 & 0 & 0 & 1 & 0 \\
Exterior Penetrations & 1 & 1 & 2 & 4 & 1 \\
Joinery Installations Issues & 1 & 8 & 3 & 12 & 3 \\
Firewall / Cladding & 4 & 5 & 3 & 12 & 3 \\
Plumbing issues & 4 & 8 & 2 & 14 & 4 \\
Hold-downs and Noggings & 7 & 6 & 4 & 17 & 5 \\
Pressure Seals & 4 & 4 & 12 & 20 & 6 \\
Galvanized shower angle & 5 & 10 & 6 & 21 & 6 \\
Building not weather tight & 3 & 14 & 8 & 25 & 7 \\
Insulation Issues & 8 & 12 & 6 & 26 & 7 \\
Framing Issues & 3 & 20 & 9 & 32 & 9 \\
Braces remediation & 13 & 8 & 11 & 32 & 9 \\
Site not Ready & 21 & 13 & 9 & 43 & 12 \\
Moisture too high & 8 & 15 & 21 & 44 & 12 \\
Outstanding Paperwork & 20 & 21 & 17 & 58 & 16 \\
Grand Total & 103 & 145 & 113 & 361 & 100 \\
\hline
\end{tabular}

\section{3 “Framing" Inspection Stage}

A total of 389 samples of failed inspections are presented in Table 3 with 147, 134, and 108 samples taken from R1, R2, and R3, respectively. There are 15 reasons for failures associated with Framing. Comparable to pre-line, the most common reason for failed inspection in framing inspection was outstanding paperwork (17\% of the time). Since the introduction of a policy that enforces the submission of the relevant paperwork to establish compliance, it has become an area that builders have struggled to achieve compliance. The second most common reason for failed framing inspection was structural issues regarding lintels sizes and fixings that don't match up with the design or were not fixed properly relative to the site wind zone design. In addition to lintels, another feature that contributes to this result were beams. Brace elements make the top three reasons for the failure of framing inspections. Braces are expected to be completed and fixed before inspections. Inspectors would only allow wrapping of buildings after all brace elements are fixed to reinforce and brace buildings. The fourth most common reason for failings in framing inspections is poor top and bottom plate fixings and hold-downs, an issue that occurs $12 \%$ of the time. Bottom and Top plate fixings are significant for the structural integrity of the building. 
Table 3. Common reasons for Failed Framing inspections.

\begin{tabular}{lccccc}
\hline Framing reasons for failure & R1 & R2 & R3 & Total & Percent \\
\hline Firewall & 2 & 0 & 1 & 3 & $1 \%$ \\
Ceiling Battens & 2 & 0 & 1 & 3 & $1 \%$ \\
Safety & 1 & 2 & 0 & 3 & $1 \%$ \\
Treatment of Timber & 4 & 1 & 0 & 5 & $1 \%$ \\
Moisture control & 4 & 2 & 3 & 9 & $2 \%$ \\
Substrate Issues & 1 & 3 & 7 & 11 & $3 \%$ \\
Details required & 6 & 4 & 3 & 13 & $3 \%$ \\
Site not ready & 5 & 1 & 10 & 16 & $4 \%$ \\
Studs/ Trimming/ walls & 7 & 3 & 7 & 17 & $4 \%$ \\
Subfloor/mid-floor framing issues & 18 & 15 & 4 & 37 & $10 \%$ \\
Roofing fixings installation & 22 & 17 & 1 & 40 & $10 \%$ \\
Bottom \& Top Plate Fixings & 14 & 17 & 16 & 47 & $12 \%$ \\
Brace Elements & 18 & 22 & 13 & 53 & $14 \%$ \\
Lintel Issues/ Beams/ point-loads & 19 & 23 & 22 & 64 & $16 \%$ \\
Paperwork Outstanding & 24 & 24 & 20 & 68 & $17 \%$ \\
Grand Total & 147 & 134 & 108 & 389 & $100 \%$ \\
\hline
\end{tabular}

Table 4. Common reasons for Failed Foundation inspections.

\begin{tabular}{lccccc}
\hline Foundation & R1 & R2 & R3 & Total & $\begin{array}{c}\text { Total } \\
\text { \% }\end{array}$ \\
\hline Safety & 1 & 0 & 1 & 2 & 1 \\
Brace Piles & 3 & 2 & 2 & 7 & 3 \\
Designers Details & 4 & 2 & 3 & 9 & 4 \\
Drains and Bridging & 2 & 3 & 5 & 10 & 4 \\
Piles holes not as per plan & 2 & 3 & 6 & 11 & 5 \\
Ground stability/ bearing/ conditions & 6 & 2 & 8 & 16 & 7 \\
Piles /Holes /Depths issues & 11 & 5 & 8 & 24 & 11 \\
Footing/ Sizes / Reinforcing & 9 & 8 & 8 & 25 & 11 \\
Incorrect Inspection & 10 & 10 & 14 & 34 & 15 \\
Site not Ready & 10 & 21 & 7 & 38 & 17 \\
Paperwork Outstanding & 22 & 15 & 11 & 48 & 21 \\
Grand Total & 80 & 71 & 73 & 224 & 100 \\
\hline
\end{tabular}

\section{4 "Foundation" Inspection Stage}

A sample of 224 failed foundation inspections was reviewed for this aspect. There were 11 reasons for failure during this stage of construction. Table 4 shows that outstanding paperwork was a common reason for failure, which occurred $21 \%$ of the time. The second most common reason for failed foundation inspections was the lack of readiness of the building sites. Moreover, in reinforced concrete foundations, reinforcing steel may not have been correctly installed, or the wrong size and type have been installed (see Table 4). Thirdly, $15 \%$ of all foundation inspections fail because of incorrect inspection day bookings, especially with slab inspections, subfloor framing, and under-slab plumbing being wrongly booked. The fourth common reason for failing is the foundation footing itself with respect to size and reinforcing. This reason also applies to piles, holes, and depth issues that make up $11 \%$ of failed inspections at the foundation stage.

\section{CONCLUSION}

The aim of the current study was to provide some insight into the reasons for failed inspections in residential buildings in New Zealand. Thus, highlighting key areas of focus necessary to enhance performance. Information on failed inspections would need to be made available to potential 
homeowners and developers to understand the dynamics behind the construction of new dwellings. Historical inspection records may be useful in providing information for future performance issues connected to buildings during their life use. The current research generated a list of the common reasons for failed inspections at four inspections stages: exterior cladding integrity and penetrations, outstanding paperwork, smoke alarms, handrails and barriers, site not ready, framing moisture too high, brace elements, lintels and beams, top and bottom plate fixings, incorrect booking and footing and piles systems. This list is largely of a technical nature except for outstanding paperwork and incorrect bookings, which are administrative in nature. Collating of inspection records during construction into property information will be useful. Such a property information file that is obtained before purchase or when engaging in any long-term investment will be critical to the property-in-use. At the very least, such information may ensure property owners' peace of mind knowing that their investment was well constructed, sound, and built to last. For BCAs, continuous analysis of inspection records will expose even more critical areas of improvement within the residential building industry, to focus on continuous improvement and customer support in the future.

\section{References}

Abdul-Rahman, H., Wang, C., Lincoln, C. W., and Khoo, Y. M., Defects in Affordable Housing Projects in Klang Valley, Malaysia, Journal of Performance of Constructed Facilities, 28(2), 272-285, 2014.

Carretero-Ayuso, M. J., Moreno-Cansado, A., and García-Sanz-Calcedo, J., An Analysis of Technical Facilities Failures in Modern Spanish Houses, Building Services Engineering Research and Technology, 38(4), 490-498, 2017.

Chong, W. K., and Low, S. P., Assessment of Defects at Construction and Occupancy Stages, Journal of Performance of Constructed Facilities, 19(4), 283-289, 2005.

Forcada, N., Macarulla, M., Gangolells, M., and Casals, M., Assessment of Construction Defects in Residential Buildings in Spain, Building Research and Information, 24(5), 629-640, 2014.

Jonsson, A. Z., and Gunnelin, R. H., Defects in Newly Constructed Residential Buildings: Owners' Perspective, International Journal of Building Pathology and Adaptation, 37(2), 163-185, 2019.

Lundkvist, R., Meiling, J. H., and Sandberg, M., A Proactive Plan-Do-Check-Act Approach to Defect Management Based On a Swedish Construction Project, Construction Management and Economic, 32(11), 1051-1065, 2014.

Page, I. C., Defects in New Houses, Build, 123(37), April/May, 2011.

Page, I. C., New House Construction Quality Survey 2014, 2015. BRANZ Study Report SR335, Judgeford, New Zealand: BRANZ Ltd. Retrieved from http://www.branz.co.nz/ on Oct 2020.

Rotimi, F. E., An Evaluative Framework for Defects in New Residential Buildings: The New Zealand Case, PhD Thesis, Auckland University of Technology, Auckland, 2013.

Tagiilima, J., Investigating Failings in Residential Building Inspections During Construction, PhD Thesis, Auckland University of Technology, Auckland, 2016.

Tagiilima, J., and Rotimi F. E., Analyzing Building Compliance Reports: A New Zealand Study, AUBEA Conference, Singapore, 38-47, September, 26-28, 2018.

Wardle, T., and Duncan, A., Prioritizing Quality: Literature Review of Common Residential Housing Defects, BRANZ Study Report SR387, Judgeford, New Zealand: BRANZ Ltd., 2017. Retrieved from https://www.branz.co.nz/ on Oct 2020. 